\title{
ERINEVUS JA ERISTAMATUS
}

Kohanimed ilmuvad eesti kirjalikku traditsiooni alates XIII sajandist. Ligi 500 kohanime on kirja pandud Taani hindamisraamatu (Liber Census Daniae, edaspidi LCD) eesti lehekülgedel. Ehkki kohanimesid leidub ka järgnevate sajandite dokumentides ja ürikutes, tulevad nad hulgana esile alates XVI sajandist, kust algavad vakuraamatud. LCD nimistu on avaldatud trükis korduvalt. XVI sajandi vakuraamatuist on avaldatud näiteks Läänemaa vanim vakuraamat ning katkeid Kullamaa ja Järvamaa vakuraamatuist.

Peamiselt on XVI sajandi vakuraamatud siiski saadaval portaalis Saaga käekirjaliselt. Käekirjalised vakuraamatud on kirja pannud võõrkeelsed kirjurid, säilinud eksemplarid näivad olevat ümberkirjutused kas terveist raamatuist või välimärkmeist.

Kogu nimeteadus lähtub eeldusest, et pärisnimed on tekkinud üldnimedest. Etümoloogiline uurimistöö püüab leida neid üldnimesid, mis võiks pärisnimedele aluseks olla, kasutades pärisnimede (näiteks kohanimede, siin külanimede) varasemaid kirjapanekuid. Siin tekib tõlgendamisküsimusi.

Näited allpool on valikulised ega anna käsitletavast nimeelemendist kõiki esinemisjuhtumeid, mis tulevad ilmsiks peagi valmivas Eesti kohanimeraamatu andmebaasis (EKNR), mille lähtenimestiku on koostanud Peeter Päll. EKNR-i märksõnastikus on 12 Mõisaküla, igaühel ainult selle ühe kohaga seotud nimi (seega nimeteooria seisukohalt 12 homonüümi, mis on laiali paisatud erinevaisse geograafilistesse kohtadesse), 4 Mõisamaa küla, 2 Mõisaaseme küla ja 2 Kodasema küla (vastavalt 4,2 ja 2 homonüümi). Tegelikult on neid nimetüüpe rohkem, aga kõik pole pääsenud märksõnastikku ega tulevasse raamatussegi.

Näiteid nimede kohta, kus kirjapanekuis tuleb esile oletatav ase : aseme. Kohamääratluses on esimene kihelkond, teine praegune vald. Vaadelgem näiteid.

A. Mõisimaa Kirbla, Lihula vald. 1565 Mоуßеаßm. Kui arhivaali teraselt vaadata, siis on seal üsna selges-

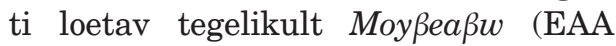
1.2.932:12, L10; vt näidet 1). Koguteoses „Läänemaa” (1938: 272) aastaarvuta antud Moiszeaszem võib olla sellesama 1565 . aasta kirjapaneku variantne tõlgendus. Selge see, et kõik need kirjakujud on tagasi viidavad nimele *Mõisaaseme, ehkki peab oletama, et $w$ oli ümberkirjutusviga ( $w$ ja $m$ lähevad käekirjas kergesti segamini).

Oletus põhineb ka sellel, et mõeldav nime teine komponent asu ei esine teadaolevalt selles positsioonis eesti kohanimedes, vaid ainult esikomponendina. Jääb üle tähenduslikult sobiv ase : aseme.

B. Mõisaküla Lääne-Nigula, LääneNigula vald. XVII sajandi lõpul on Uugla mõisa all märgitud kõrvuti külad Moißaße By ja Orro By. Viimane olevat kujunenud asulast, mida 1627. aastal nimetatud Rotsi-Udenkül. Esimene nimi (?*Mõisaaseme) sai tõenäoliselt aluseks Mõisaküla nimele. Tänapäeval on tuntud Mõisaaseme küla Rapla vallas ja aastal 1977 Rasiverega liidetud Mõisaaseme küla Anija vallas.

C. Vanamõisa Kirbla, Lihula vald. Koguteoses „Läänemaa” antud Vanamõisa varasem nimekuju Wanhamoiszeaszw 


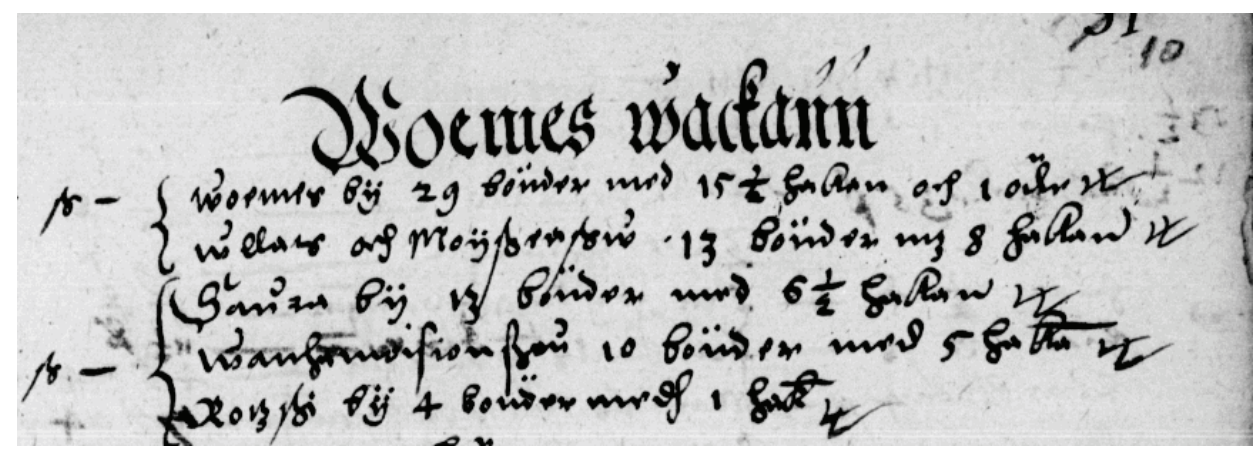

N äi d e 1. Moyßeaßw (EAA 1.2.932:12, L10).

(1938: 272) võib olla 1565. aasta kirjapaneku Wanhemoisioaßeu, siinse autori tõlgenduses Wanhemoisioaßen, variant, kirjapanekut võib lugeda ka Wanhamoisioaßm, kui oletada, et siingi on olnud algses käsikirjas $m$ (EAA 1.2.932:12, L10). Ka siin võiks aluseks olla ase : aseme: *Vanamõisa ase või *Vanamõisaaseme.

D. Mõisamaa Märjamaa, Rapla vald. 1586 Mausa Assa (Rev 1586: 57), 1726 Moisama (Rev 1725/26: 54). Tõenäoliselt on siingi teise osa -maa aluseks olnud ase : aseme.

Nimeloendina sünkroonias ei erine Mõisaküla Mõisakülast ega Vanamõisa Vanamõisast, kuid nende vahel on nähtamatuks pakitud erinevus: diakroonias erineb siinne Mõisaküla mitmest teisest Mõisakülast, siinne Vanamõisa erineb mõnest muust Vanamõisast, kus algseltki on osis ase puudunud, ja siinne Mõisamaa nendest Mõisamaadest, kus teine osa on lähtunud sõnast maa. Teise astme erinevus tuleb välja käekirjaliste nimekirjapanekute tõlgendamisel, kus tuleb teha oletusi $u \sim n$ või $w \sim m$. Teise astme erinevus hargneb ja elab oma elu, kuid sellel ma siin ei peatu.

Järgnevais näiteis on liigisõna ase kas kadunud või andnud nimelõpu -ma(a), mis on selle liigisõna puhul üsna tavaline.
E. Külasema Muhu, Muhu vald. 1570 Kullesme Ahndreß (SFM: 38), 1756 Külla Asseme (Kallasmaa 1996: 157), 1798 Küllasma (Mellin 1791-1798). Nime aluseks on tõenäoliselt sõnad küla + ase : aseme, vrd Tartumaal Külaaseme küla. Ka Viljandimaal Helme kihelkonnas Kärstna mõisa alal on olnud *Külaaseme: 1624 Killa Asima (Rev 1624: 84), 1798 Küllaassem (Mellin 1791-1798), 1839 Kullaassem (Rücker), tänapäeval on enam-vähem sama koha peal Põrga küla.

F. Kodasema Peetri, RoosnaAlliku vald. 1586 Koddaszem (UngernSternberg 1912: 66), 1796 Koddasim, Koddaassem M. (Mellin 1791-1798). Siin aluseks koda + ase : aseme.

G. Kodasema Keila, Saue vald. 1457 Coddesam (Johansen 1929: 74), 1796 Koddaassem (Mellin 1791-1798), aluseks koda + ase : aseme.

H. Kodesmaa Pärnu-Jaagupi, Halinga vald. 1515 Peter Janspockke Kottesme (Stackelberg 1926: 208), 1839 Koddasma (Rücker). Eelmise kahe põhjal võiks oletada siingi sama arengut, kuid võrdluseks ka nimi Kodismaa.

I. Kodismaa Laiuse, Torma vald. Valdek Palli (1969: 76) arvates võiks Kodismaa kujunemise seletamisel panna esikohale võimaluse jagada nimi 
kaheks ja tuua esikomponendi vasteks soome sõna kodis : kodiksen 'kodukoht; krunt, maatükk'. Soome murretes esineb ka liitsõna kodismaa ( kolismaa) 'taluhoonete lähedal olev väike põld'. Lauri Kettunen (1955: 124) on Kodismaa esiosa ühendanud koda mitmuse tüvega ja teise osa tuletanud sõnast ase : aseme, mis on läbi teinud kohanimedes esineva eriarengu. Ka Pall ei välista seda võimalust, tuues võrdluseks Rapla LCD-s esineva nime Kotoassen, mis juba XV sajandil oli kirjapanekuis lühenenud kujudele Kottis, Kottesch, Kottys (Pall 1969: 76). Vrd ka Põhja-Tartumaalt Kursilt Kodasme t: 1753 Kodda asseme Jurri (Pall 1969: 75).

Kokkuvõttena võib öelda, et näidetes A, B, C ja D avaneb praegune nähtamatuks pakitud erinevus (näiteks osa ajaloolisest mälust) nähtava erinevusena diakroonias. Sünkroonias on nimed Külasema ja Kodasema juba tõlgendatavad Külase/ma ja Kodase/ma. Näited E, F, G ja I paljastavad, et teatud juhtudel on kohaajalugu märkiv osis mingil põhjusel (muutununa) säilinud tänapäevani.

Sügavamal asuv nimeandmisprintsiip on olnud kõigil käsitletud juhtudel sama: asustusüksus on (ajutiselt) lakanud. Nimeelemendil -ase, -aseme on kalduvus kaduda (või nimetervi- kuna vahetuda nagu Helme toponüüm *Külaaseme või LCD Kotoassen) või muutuda juhul, kui asustusüksus taaselustatakse. Muutumise korral lähevad need nimed enamasti kohanimetüüpi, mis lõpeb osisega $-m a(a)$.

Siin kirjutises ei ole seni arvestatud erinevusega, et geograafiliselt asuvad kõik need paigad eri kohtades (paiknemise erinevus), s.o reaalses maailmas. Sünkroonias nähtamatuks pakitud ajaloolist mälu esitava keelelise erinevuse kompenseerib ruumiline erinevus. Sõnad mõis, küla, koda (kodu) ja maa on eestlasele olnud võimsad markerid, mis üldjuhul ei ole vajanud külanimedes lisaks negatiivsevõitu konnotatsiooniga sõna -ase. Üksiknimedes see element siiski leidub tänini, lisaks ülalmainituile: alles 1977 liideti Kastnaga Vanaaseme (Vändra, Lelle vald) küla, 1839 veel taluna Wannaasseme.

Artikkel on kirjutatud programmi „Eesti keel ja kultuurimälu II" ning selle poolt rahastatava projekti „Eesti kohanimede etümoloogilise sõnaraamatu toimetamine" raames.

MARJA KALLASMAA

\section{Lühendid}

$\mathrm{EAA}=$ Eesti Ajalooarhiiv.

EKNR = Marit Alas, Marianne Blomqvist, Enn Ernits, Mariko Faster, Marje Joalaid, Marja Kallasmaa, Arvis Kiristaja, Marge Kuslap, Tiina Laansalu, Karl Pajusalu, Valdek Pall, Fred Puss, Peeter Päll, Evar Saar, Urmas Sutrop. Eesti kohanimeraamatu andmebaas.

\section{Kirjandus}

Johanse n, Paul 1929. Katkendid Tallinna esimestest turberaamatutest. 1365-1458. (Tallinna linna arhiivi väljaanded 4.) Tallinn: Tallinna Eesti Kirjastus-Ühisus.

Kall asmaa, Marja 1996. Saaremaa kohanimed I. Tallinn: Eesti Keele Instituut. 
Kettunen, Lauri 1955. Etymologische Untersuchung über estnische Ortsnamen. (Suomalaisen tiedeakademian toimituksia. Sarja B, 90.1.) Helsinki: Suomalainen tiedeakatemia.

Läänemaa. Maateaduslik, majanduslik ja ajalooline kirjeldus. Üldosa. Eesti VIII. Tartu: Eesti Kirjanduse Selts, 1938.

Mellin, Ludwig August 1791-1798. Atlas von Liefland oder von den beyden Gouvernementen und Herzogthümern Lief- und Ehstland und der Provinz Oesel. Riga-Leipzig.

P a l l, Valdek 1969. Põhja-Tartumaa kohanimed. I. Toim Madis Norvik. Eesti NSV Teaduste Akadeemia Keele ja Kirjanduse Instituut. Tallinn: Valgus.

Rev 1586 = Ungern Sternberg, Paul Frhr. von 1915. Die Revision vom J. 1586 und die Befragung vom J. 1589. - Beiträge zur Kunde Est-, Liv- und Kurlands. Band VIII, Heft 1 u. 2. Reval.

Rev 1624 = Das Pernauer Land 1624. Hrsg. O. Roslavlev. Hefte zur Landeskunde Estlands. Heft 2. WolfratshausenWaldram, 1967.

Rev 1725/26 = Eestimaa 1725.-1726. a. adramaarevisjon. Läänemaa. Allikapublikatsioon. Tallinn, 1990.
$\mathrm{R} \ddot{\mathrm{u}} \mathrm{c} \mathrm{k}$ e r $=$ Specialcharte von Livland in 6 Blättern. Bearbeitet und herausgegeben auf Veranstaltung der Livländischen gemeinnützigen und ökonomischen Societät; nach Struves astronomischtrigonometrischen Vermessung und den vollständigen Specialmessungen gezeichnet von C. G. Rücker; gestochen im Topographischen Depôt des Kaiserlichen Generalstabes. (1 : 184 275.) Sankt Petersburg: Livländische gemeinnützige und ökonomische Societät, 1839.

SFM = Saaremaa Maasilinna foogtkonna maaraamatud 1569-1571. Allikapublikatsioon. Tallinn, 1992.

Stackelberg, F. Baron 1926. Der Landbesitz im Kreise Pernau zur Ordenzeit. - Sitzungsberichte der Altertumforschenden Gesellschaft zu Pernau, kd 8, 1914-1925, lk 143-282.

Ungern-Sternberg, Paul Freiherrn von 1912. Materialien zur Gütergeschichte Jerwens für die ältere schwedische Zeit bis zur Abfassung der ältesten uns erhaltenen Munster- und Rossdienstrollen Estlands. - Beiträge zur Kunde Est-, Liv- und Kurlands, kd VII, nr 4. Reval. 